Research paper

\title{
A diaminoethane motif bearing low molecular weight polymer as a new nucleic acid delivery agent
}

\author{
Aykut Zelcak $^{\mathrm{a}, \mathrm{b}}$, Yagmur Ceren Unal ${ }^{\mathrm{c}}$, Gulistan Mese ${ }^{\mathrm{c}}$, Volga Bulmus ${ }^{\mathrm{a},}$ \\ ${ }^{\text {a }}$ Department of Bioengineering, Izmir Institute of Technology, Urla, Izmir, 35430, Turkey \\ ${ }^{\mathrm{b}}$ Biotechnology and Bioengineering Graduate Programme, Izmir Institute of Technology, Urla, Izmir, 35430, Turkey \\ ${ }^{\mathrm{c}}$ Department of Molecular Biology and Genetics, Izmir Institute of Technology, Urla, Izmir, 35430, Turkey
}

\section{A R T I C L E I N F O}

\section{Keywords:}

siRNA delivery

Gene delivery

Cationic polymers

Gene therapy

PEI

\begin{abstract}
A B S T R A C T
Among polymer-based gene delivery systems, poly(ethylene imine) (PEI) stands out as an effective polycation. However, the toxic effects of PEI especially at higher molecular weights limit its usage. Although the effects of PEI's architecture and molecular weight on gene delivery is controversial in literature, low molecular weight PEI appears to be efficient at transfection while having lower toxicity. Herein, as an alternative to low molecular weight, linear PEI, a methacrylate polymer bearing diamimoethane motifs, poly(2-((2-aminoethyl)amino)ethyl methacrylate) (P(AEAEMA)), was evaluated in vitro as a new nucleic acid delivery agent. P(AEAEMA) (8 kDa) showed low toxicity on Skov-3-luc and NIH/3T3 cell lines at polymer concentrations where PEI (8 kDa) was highly toxic. P(AEAEMA) could efficiently form complexes with siRNA at an N/P ratio of 2 as shown by gel electrophoresis. The diameter of P(AEAEMA)-siRNA complexes was found to be significantly lower than PEIsiRNA complexes almost at all tested N/P ratios. P(AEAEMA) could improve the stability of siRNA in serum containing media by protecting the siRNA against serum nucleases. siRNA and pDNA transfection efficiency of $P$ (AEAEMA) on luciferase expressing Skov-3-luc cell line and HEK 293T cell line, respectively was found to be comparable to well-known nucleic acid carrier, PEI. The transfection efficiency of both P(AEAEMA) and PEI was found to be cell-type-dependent. None of the polymers were able to transfect MDA-MB-231 cells with siRNA or pDNA.
\end{abstract}

\section{Introduction}

Gene therapy via gene insertion or interference offers an enormously promising modality for treatment of a diverse range of diseases. The current toolbox of gene therapy contains a number of nucleic acid structures including plasmid DNA (pDNA), messenger RNA, small interfering RNA (siRNA) and antisense oligonucleotides, some of which have been approved for treatment of certain kinds of cancer, viral infections and genetic diseases [1]. Among these structures, pDNA is used to introduce genes to cells to increase or correct target gene expression [2-4], whereas siRNA molecules are used to trigger specific gene silencing [5-10]. Although they have significant structural differences, both these nucleic acids suffer from certain common problems such as poor in vivo stability and cellular uptake $[11,12]$. Various delivery systems have been developed and used to protect nucleic acids against degradation and efficiently transport into the cell cytosol [13-17]. Although some delivery agents have shown successful results in both in vitro and in vivo applications, developing a safe and effective delivery system is still a major goal in gene therapy.

As nucleic acid carriers, cationic polymers are widely used because of their certain features. They can form complexes with nucleic acids via simple electrostatic interactions, be tailored for desired applications and show relatively high transfection efficiency [18,19]. Among polymer-based delivery systems, polyethyleneimine (PEI) has stood out as an effective polycation in the field [20,21]. The high buffering capacity of PEI enables endosomal escape via possible 'proton sponge effect' and this results in high transfection efficiency [21]. However, PEI is non-degradable and the molecular weight of PEI affects the cytotoxicity and gene transfer activity. The toxic effects of PEI especially at higher molecular weights limit its usage in the delivery systems [22]. Although the effects of PEI's architecture and molecular weight on gene delivery are controversial in literature, low molecular weight, linear PEI has been shown to have superior transfection efficiency while having lower toxicity in a significant number of publications [23-27].

\footnotetext{
* Corresponding author. Department of Bioengineering, Izmir Institute of Technology, Urla, Izmir, 35430, Turkey.

E-mail address: volgabulmus@iyte.edu.tr (V. Bulmus).
} 
Several cationic polymers, including PEI, that are known to be successful at endosomal escape and nucleic acid transfection, contain the repeating units of the same structural motif, i.e. diaminoethane motif [28]. Diaminoethane (DET) motif displays the two-step protonation property providing the parent polymers high proton sponge capacity and membrane destabilization capability during endosomal acidification [29,30]. While the motif is partially protonated at physiological $\mathrm{pH}$, once it is inside the endosome it becomes fully protonated. This $\mathrm{pH}$-dependent protonation ability of the motif is known to provide high transfection efficiency to the carrier system [29-33].

A new DET motif containing methacrylate polymer, poly(2-((2aminoethyl)amino)ethyl methacrylate) (P(AEAEMA)), was previously synthesized as a potential gene delivery vector [34]. Different from existing DET motif containing polymers in the literature, P(AEAEMA) have been synthesized by reversible addition-fragmentation chain transfer (RAFT) polymerization which provides in general several advantages such as ease in synthesis of complex architectures and modifiability via functional end groups. In addition to these synthetic advantages, this new polymer combines DET motifs with a relatively hydrophobic methacrylate backbone, envisioning higher particulate stability after complexing with genetic material and enhanced transfection ability [35]. Moreover, P(AEAEMA) structure has DET motifs linked to the backbone via an ester linkage, providing partial degradability to the polymer. We previously reported RAFT synthesis of $P$ (AEAEMA) and a few preliminary results showing the complex forming ability of P(AEAEMA) with a 700-bp DNA fragment [34]. It is well-known that the performance of delivery systems varies drastically when it comes to siRNA due to short and rigid nature of siRNA [36-38]. In this work, siRNA and pDNA delivery potential of P(AEAEMA) has been evaluated and compared to PEI that is known as a gold-standard in the field. The molecular weight of P(AEAEMA) synthesized in this study was intentionally kept low, similar to low molecular weight, linear PEI, to be able to compare the efficiency of the polymers. The complex forming ability of P(AEAEMA) with siRNA was determined via gel electrophoresis. Size and surface charge of the polyplexes were also investigated using dynamic light scattering (DLS) and electrophoretic light scattering (ELS), respectively. Serum stability of the polyplexes was also determined by gel electrophoresis. Toxicity, siRNA and pDNA transfection efficiency of P(AEAEMA) was also investigated and compared to PEI. The results have been presented below.

\section{Experimental}

\subsection{Materials}

N-Hydroxyethylethylenediamine (99\% purity), di-tert-butyl dicarbonate and methacryloyl chloride were purchased from Aldrich. Chain transfer agent, 4-cyano-4-(phenylcarbonothioylthio) pentanoic acid (CPADB) was purchased from Aldrich. The initiator 2,2'-azobis(2methylpropionitrile) (AIBN) was used after recrystallization twice in methanol. Silica gel (pore size $60 \AA$, 70-230 mesh) was purchased from Fluka. Mono- and di-basic phosphate salts were purchased from Merck. Linear polyethyleneimine (PEI; Mn: $8 \mathrm{kDa}$ ) was purchased from SigmaAldrich.

Toluene, ethylacetate, hexane, dichloromethane (DCM), trifluoroacetic acid (TFA), deuterium oxide $\left(\mathrm{D}_{2} \mathrm{O}\right)$, deuterium chloroform $\left(\mathrm{CDCl}_{3}\right)$, dimethyl sulfoxide-d6, triethylamine (TEA), hexylamine (HEA), diethyl ether, methanol and $\mathrm{N}^{\prime}, \mathrm{N}^{\prime}$-dimethylacetamide (DMAc, HPCL grade $\geq 99.9 \%$ ) were purchased from Sigma. The dialysis membrane $(\mathrm{MWCO}=1000 \mathrm{Da})$ was purchased from Spectrum $\circledast$ Laboratories.

DMEM (Dulbecco's Modified Eagle's Medium) and L-glutamine were purchased from Lonza. FBS (Fetal Bovine Serum) was purchased from Sigma. Penicillin-streptomycin, non-essential amino acids and TrypsinEDTA were obtained from Biological Industries. 3-(4,5-dimethylthiazol-2-yl)-2,5-diphenyl tetrazolium bromide (MTT), dimethyl sulfoxide (DMSO) and phosphate buffer saline (PBS) were purchased from Sigma.
Skov-3-Luc and MDA-MB-231-Luc cell lines were kindly donated by Prof. Dr. Sacide ALTINKAYA (Izmir Institute of Technology) and Prof. Özgür ŞAHIN (Bilkent University), respectively. HEK 293-T and MDAMB-231 cell lines were kindly provided by Assoc. Prof. Ozden YalcinOzuysal (Izmir Institute of Technology). Luciferase assay kit was purchased from Promega. Commercial transfection reagents, Lipofectamine RNAimax and DharmaFECT 3, were purchased from Invitrogen and Dharmacon, respectively. Negative control siRNA, siGENOME Nontargeting siRNA \#3, was purchased from Dharmacon. Standard desalted siRNA (sense: 5'-GCUAUGGGCUGAAUACAAAUU-3'; antisense: 5'UUUGUAUUCAGCCCAUAGCUU- ${ }^{\prime}$ ) was purchased from IDT DNA. pIRES2-EGFP (Clontech Laboratories, USA) was used in pDNA transfection assays. Agarose and ethidium bromide were purchased from Sigma. 6 X loading dye solution and DNA markers (100bp and $1 \mathrm{~kb}$ ) were purchased from Fermantas.

\subsection{Instrumental methods}

\subsubsection{Nuclear magnetic resonance (NMR) spectroscopy}

The chemical structure of synthesized compounds was determined using ${ }^{1} \mathrm{H}$ NMR spectroscopy (Varian, VNMRJ 400 spectrometer). $\mathrm{CDCl}_{3}$ and $\left(\mathrm{CD}_{3}\right)_{2} \mathrm{SO}$ were used as NMR solvents. NMR samples were prepared by dissolving the sample in a proper solvent at a concentration of $6 \mathrm{mg}$ / $\mathrm{ml}$.

\subsubsection{Gel permeation chromatography (GPC)}

Molecular weight and dispersity ( $Đ$ ) of the polymer were determined by GPC. A Shimadzu modular system comprising an SIL-10AD auto injector, PSS Gram $30 \AA$ and $100 \AA(10 \mu \mathrm{M}, 8 \times 300 \mathrm{~mm})$ columns and an RID-10A refractive-index detector calibrated with low dispersity poly (methyl methacrylate) standards (410-67000 g/mol) were used. $0.05 \%$ $\mathrm{w} / \mathrm{v}$ lithium bromide containing DMAc was employed as mobile phase.

\subsubsection{Agarose gel electrophoresis}

Thermo Scientific Owl ${ }^{\mathrm{TM}}$ EasyCast ${ }^{\mathrm{TM}} \mathrm{B} 1 \mathrm{mini}$ gel system was used to investigate the complex forming ability of polymers with siRNA via agarose gel electrophoresis.

\subsubsection{Dynamic and electrophoretic light scattering}

The hydrodynamic diameter and surface charge of the polyplexes were determined using a NanoPlus DLS Nano Particle Size and Zeta Potential Analyzer (Micromeritics) (measurement range for size: $0.1 \mathrm{~nm}$ to $12.30 \mu \mathrm{m}$ for zeta -500 to $+500 \mathrm{mV}$; laser source: diode laser; laser wavelength: $660 \mathrm{~nm}$; laser power: dual laser $30 \mathrm{~mW}+70 \mathrm{~mW}$ ). Dynamic Light Scattering (DLS) measurements were performed after an equilibration time of $120 \mathrm{~s} .2 \times 70$ runs were carried out at $25^{\circ} \mathrm{C}$. The counts were detected at an angle of $165^{\circ}$. Each measurement was performed in duplicate. Electrophoretic Light Scattering was used to determine the surface charge ( $\zeta$-potential) of the particles. Smoluchowski equation was used to calculate zeta potential from the mobility. 5 runs were carried out for each measurement. Each experiment was performed in triplicate at $25^{\circ} \mathrm{C}$.

\subsubsection{Microplate reader}

Thermo Electron Corporation Varioskan microplate reader was used for the measurement of absorbance and luminescence for MTT and luciferase assays, respectively.

\subsubsection{Flow cytometry and fluorescence microscopy}

Flow cytometry (BD FACSCanto TM, BD Biosciences) and fluorescence microscopy (Olympus IX83) were used to determine pDNA transfection efficiency of the polymers. For both P(AEAEMA)- $8 \mathrm{kDa}$ and PEI-8 $\mathrm{kDa}$, completely the same experimental and instrumental set-up were employed. 


\subsection{Methods}

\subsubsection{Synthesis of poly(2-((2-aminoethyl)amino)ethyl methacrylate) ( $P$ (AEAEMA))}

First, the monomer 2-((tert-butoxycarbonyl) (2-((tert-butoxycarbonyl)amino)ethyl)amino)ethyl methacrylate (BocAEAEMA) was synthesized according to the procedure reported by Kurtulus et al. [34]. Briefly, N-(2-hydroxyethyl)ethylenediamine $(0.024 \mathrm{~mol})$ and di-tert-butyl dicarbonate $(0.048 \mathrm{~mol})$ were separately dissolved in dry DCM (40 ml). Di-tert-butyl dicarbonate solution was added dropwise into $\mathrm{N}$-(2- hydroxyethyl)ethylenediamine solution at $-10{ }^{\circ} \mathrm{C}$. The solution was purged with nitrogen for $3 \mathrm{~h}$ and stirred for $24 \mathrm{~h}$ at room temperature under nitrogen atmosphere. After the reaction, the precipitate was removed by filtration. Water-DCM extraction was performed to remove unreacted starting compound. Tert-butyl-2-(((tert-butoxycarbonyl)amino)ethyl)(2-hydroxyethyl) carbamate (BocAEAE) was obtained after collecting the organic phase and evaporating the solvent using a rotary evaporator.

At the second step, BocAEAE was reacted with methacryloyl chloride to obtain methacrylate derivative of tert-butyl-2-(((tert-butoxycarbonyl) amino)ethyl)(2-hydroxyethyl)carbamate (BocAEAEMA). Briefly, BocAEAE (0.0154 mol) was dissolved in dry DCM at $0{ }^{\circ} \mathrm{C}$. Under nitrogen, triethylamine $(0.043 \mathrm{~mol})$ was added dropwise to the solution and the solution was allowed to stir for $30 \mathrm{~min}$. Afterwards methacryloyl chloride $(0.029 \mathrm{~mol})$ was dropped into the solution and the final solution was stirred at $0{ }^{\circ} \mathrm{C}$ for $4 \mathrm{~h}$ under nitrogen. The solution was further stirred at room temperature for $15 \mathrm{~h}$. The final product was purified by filtration, extraction and hexane-ethylacetate silica gel column chromatography as reported elsewhere [34]. Additionally, basic alumina chromatography was performed using hexane and ethyl acetate at a volume ratio of 1:1 to remove remaining methacrylic acid.

${ }^{1} \mathrm{H}$ NMR ( $\mathrm{CDCl}_{3}$, d in ppm): 6.10-5.57 (s, $\left.2 \mathrm{H}, \mathrm{CH}_{2}=\mathrm{C}\left(\mathrm{CH}_{3}\right) \mathrm{COO}-\right)$, $1.94\left(\mathrm{~s}, 3 \mathrm{H}, \mathrm{CH}_{2}=\mathrm{C}-\mathrm{CH}_{3}\right), 4.25-4.23\left(\mathrm{t}, 2 \mathrm{H},-\mathrm{COO}-\mathrm{CH}_{2}-\right), 3.50-3.26(\mathrm{t}$, $\left.6 \mathrm{H},-\mathrm{CH}_{2}-\mathrm{N}\left(\mathrm{COO}\left(\mathrm{CH}_{3}\right)_{3}-\mathrm{CH}_{2}-\mathrm{CH}_{2}-\mathrm{NH}\left(\mathrm{COO}\left(\mathrm{CH}_{3}\right)_{3}\right)\right)\right)$, 1.45-1.42 (s, $18 \mathrm{H},-\mathrm{N}\left(\mathrm{COO}-\left(\mathrm{CH}_{3}\right)_{3}\right)-\mathrm{CH}_{2}-\mathrm{CH}_{2}-\mathrm{NH}-\left(\mathrm{COO}\left(\mathrm{CH}_{3}\right)_{3}\right), 4.97-4.75(\mathrm{~s}, 1 \mathrm{H}$, $-\mathrm{CH}_{2}-\mathrm{NH}-\left(\mathrm{COO}\left(\mathrm{CH}_{3}\right)_{3}\right)$.

The synthesized monomer BocAEAEMA was polymerized via RAFT polymerization (Scheme 1). Briefly, monomer (BocAEAEMA) $(0.486$ mmol), corresponding amounts of the RAFT agent (CPADB) and initiator (AIBN) ([BocAEAEMA $] /[\mathrm{CPADB}] /[\mathrm{AIBN}]=100 / 1 / 0.25)$ were dissolved in toluene (monomer concentration of $1.2 \mathrm{M}$ ). The solution was purged with nitrogen for $20 \mathrm{~min}$, then immersed in an oil bath at $65^{\circ} \mathrm{C}$. At the end of the polymerization time $(16 \mathrm{~h})$, the reaction solution was cooled in an ice bath and exposed to air. Polymer was purified by precipitating the polymerization mixture in hexane three times. The number average molecular weight $\left(\mathrm{M}_{\mathrm{n}}\right)$ and molecular weight distribution ( $($ ) of the polymer were determined by GPC.
At the next step, (tert-butyloxycarbonyl) (Boc) groups were removed from the purified polymer by using trifluoroacetic acid (TFA) (Scheme 1). Briefly, polymer $(4.35 \mu \mathrm{mol})$ was dissolved in DCM $(1 \mathrm{ml})$ and TFA $(0.5 \mathrm{ml})$ was added into the solution at $0{ }^{\circ} \mathrm{C}$. The solution was allowed to stir for $30 \mathrm{~min}$ at room temperature. After the solvent was evaporated, the reaction mixture was washed with chloroform and diethyl ether. The deprotected polymer P(AEAEMA) was dried in vacuum oven and characterized by ${ }^{1} \mathrm{H}$ NMR spectroscopy in DMSO- $d_{6}$.

Thiocarbonylthio RAFT-end group of P(AEAEMA) was also removed from the polymer in order to prevent possible cytotoxic effects of the RAFT end-group by following a well-known protocol reported in the literature [39]. Briefly, P(AEAEMA) was reacted with methyl acrylate (MA) in the presence of hexylamine (HEA) and triethylamine (TEA) for $7 \mathrm{~h}$ under nitrogen atmosphere at room temperature ([P(AEAEMA)]/[$\mathrm{HEA}] /[\mathrm{TEA}] /[\mathrm{MA}]=1 / 10 / 10 / 3)$. The polymer was precipitated in diethyl ether and further purified by dialysis against water (MWCO $1000 \mathrm{Da}$ ). The polymer was dried using freeze-dryer and characterized by ${ }^{1} \mathrm{H}$ NMR spectroscopy in $\mathrm{D}_{2} \mathrm{O}$.

\subsubsection{Cell culture}

For cell culture experiments, Skov-3-luc (stably luciferase expressing human ovary cancer cell line), MDA-MB-231-luc (stably luciferase expressing human breast cancer cell line), HEK 293T (human embryonic kidney cell line) and NIH/3T3 (mouse fibroblast cell line) were cultured in high glucose DMEM medium supplemented with $10 \%$ fetal bovine serum (FBS), $0.1 \mathrm{mM}$ MEM Non-Essential Amino Acids, $2 \mathrm{mM}$ L-glutamine and $1 \%$ penicillin-streptomycin at $37{ }^{\circ} \mathrm{C}$ and $5 \%$ carbon dioxide in a humidified atmosphere. Subculture was performed when the cells had approximately $80 \%$ confluency.

\subsubsection{Determination of the effect of polymers on cell viability via MTT assay}

The effect of the polymers on the viability of cells was determined via MTT assay. One day prior to sample exposure, the human ovary cancer Skov-3-luc or NIH/3T3 cells were seeded at a density of $10^{4}$ cells/well in a 96-well plate. The polymer stock solutions were prepared in PBS at predetermined concentrations. $5 \mu \mathrm{l}$ of polymer stocks in PBS was added to the wells in triplicate. In positive control experiments, $5 \mu \mathrm{l}$ of PBS only was added into the wells. The cells were incubated at $37{ }^{\circ} \mathrm{C}$ and $5 \% \mathrm{CO}_{2}$ in a humidified atmosphere for 24 or $72 \mathrm{~h}$. After the incubation period, 3-(4,5-dimethylthiazol-2-yl)-2,5-diphenyl tetrazolium bromide (MTT) stock solution prepared in PBS at a concentration of $5 \mathrm{mg} / \mathrm{ml}$ was added to wells by adjusting the final concentration of dye to be $10 \%(\mathrm{v} / \mathrm{v})$. The cells were further incubated for $4 \mathrm{~h}$ in dark and humidified atmosphere at $37{ }^{\circ} \mathrm{C}$. Afterwards, the plates were centrifuged at $1800 \mathrm{rpm}$ for 10 min. The supernatants were removed by tapping gently and the formazan crystals were dissolved in DMSO. The absorbance at 570 and 690

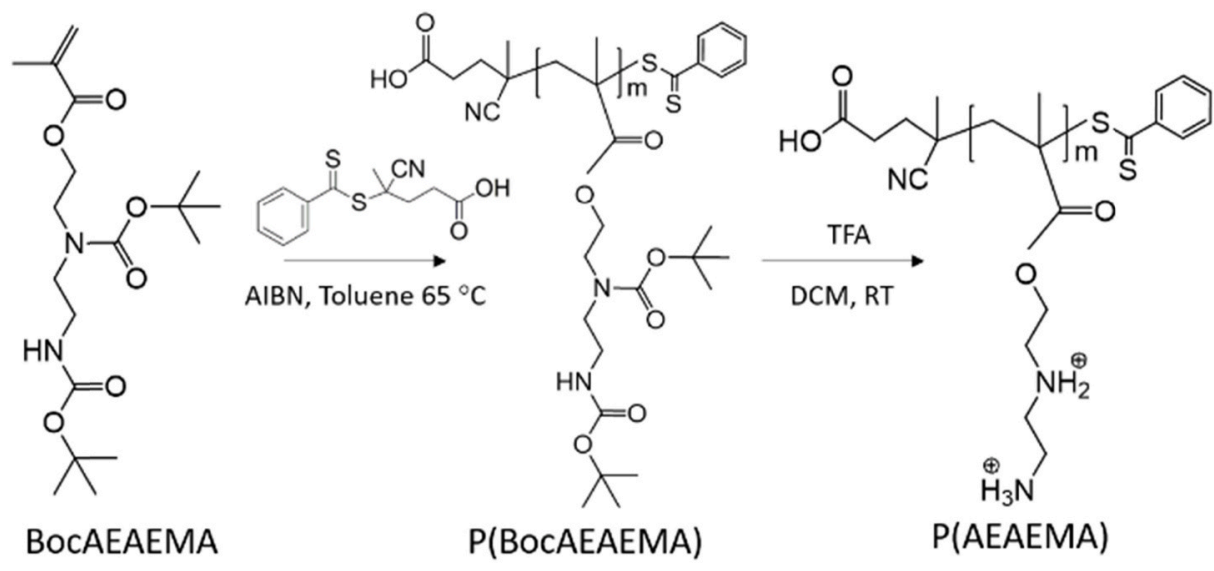

Scheme 1. Synthesis of poly(2-((2-aminoethyl)amino)ethyl methacrylate) (P(AEAEMA)). 
$\mathrm{nm}$ was determined using a microplate reader. The data were presented as mean $(\mathrm{n}=3) \pm$ standard deviation. Student's $t$-test (two-tailed) was used to analyse the data and $\mathrm{p}<0.01$ was considered statistically significant.

\subsubsection{Determination of polymer-siRNA complex formation}

The siRNA binding ability of P(AEAEMA) was investigated by agarose gel electrophoresis. The polymers were dissolved in $10 \mathrm{mM}$ phosphate buffer at $\mathrm{pH} 6$ to yield a polymer stock solution of $10^{-1} \mathrm{mM}$. Separately, siRNA was dissolved in RNase-free water at a concentration of $10 \mu \mathrm{M}$. Corresponding amounts of polymers were added to $0.02 \mathrm{nmol}$ siRNA to obtain complexes at varying nitrogen/phosphate $(\mathrm{N} / \mathrm{P}=$ moles of polymer's amine groups $(\mathrm{N}) /$ moles of nucleic acid's phosphate groups (P)) ratios (1, 2, 3, 4, 5, 10 and 30). The siRNA-polymer solutions were incubated at room temperature for $15 \mathrm{~min}$. The solutions were then mixed with 6X loading dye and loaded into $3 \%$ agarose gel stained with $0.5 \mu \mathrm{g} / \mathrm{ml}$ ethidium bromide. The gel was run at $100 \mathrm{~V}$ for $25 \mathrm{~min}$ in $1 \mathrm{X}$ TAE running buffer and analysed using UV illumination.

The particle size and zeta potential of the polyplexes were determined by NanoPlus DLS Nano Particle Size and Zeta Potential Analyzer. The polyplexes at varying N/P ratios $(2,5,10,30,50,100$ and 200) were prepared as described above. The siRNA concentration in this case was 4 $\mu \mathrm{M}$. To understand and define the complex formation better, the hydrodynamic volume of the polyplexes was measured in the media where the complexes were formed in (phosphate buffer at $\mathrm{pH}$ 6.0). For this aim, quartz micro volume cells ( $30 \mu \mathrm{l})$ were used. The zeta potential value of the same polyplexes was also determined using micro volume disposable cell $(130 \mu \mathrm{l})$ using the same instrument. The data were presented as the average ( \pm standard deviation) of three measurements.

\subsubsection{Investigation of serum stability of polymer-siRNA complexes}

The siRNA protection ability of P(AEAEMA) against serum components was investigated by agarose gel electrophoresis. The polyplexes were prepared at an N/P ratio of 2 or 10 as described above and incubated with equal volume of fetal bovine serum at $37{ }^{\circ} \mathrm{C}$ for predetermined times ( $30 \mathrm{~min}, 2 \mathrm{~h}, 4 \mathrm{~h}, 6 \mathrm{~h}$ or $24 \mathrm{~h}$ ). At the end of the corresponding incubation time, the aliquots were taken and immediately treated with $0.5 \mathrm{M}$ EDTA to stop the degradation. The aliquots were frozen and stored at $-80{ }^{\circ} \mathrm{C}$ until the analysis. SDS (2\%) was added in equal volume to the polyplex solution in order to displace the siRNA from the complex and the final solution ( $20 \mu \mathrm{l}, 0.04$ nmol siRNA) was analysed by $3 \%$ agarose gel electrophoresis. The gel was run at $100 \mathrm{~V}$ for 25 min. 0.5 M EDTA treated serum (inactivated serum) was used in control experiments. The serum stability of naked siRNA was also determined by applying the same procedure.

\subsubsection{Investigation of the transfection efficiency}

In order to determine the siRNA transfection efficiency of $\mathrm{P}$ (AEAEMA), luciferase assay was performed using Promega luciferase assay kit. Two different commercial transfection reagents (lipofectamine RNAimax and DharmaFECT 3) were used according to the manufacturer's protocol. siRNA sequence synthesized against firefly luciferase gene was used to selectively inhibit the expression of luciferase gene. A non-targeting siRNA sequence (siGENOME Non-targeting siRNA \#3) was also used as a negative control. The luciferase expression level in stably luciferase expressing Skov-3-luc or MDA-MB-231-luc cell line was evaluated using a luminometer. Cells were seeded to wells at a concentration of $10^{4}$ cells/well. After $24 \mathrm{~h}$ incubation at $37^{\circ} \mathrm{C}$ and $5 \% \mathrm{CO}_{2}$, the medium was removed and fresh complete medium without antibiotics $(95 \mu \mathrm{l})$ was added to the wells. The cells were transfected with $5 \mu \mathrm{l}$ of polyplexes at a siRNA dose of $100 \mathrm{nM}$. As a control, $5 \mu \mathrm{l}$ of $10 \mathrm{mM}$ phosphate buffer ( $\mathrm{pH} 6$ ) was added into the wells. Cells were incubated with the samples for $24 \mathrm{~h}$. Afterwards, the media were removed, fresh complete media $(100 \mu \mathrm{l})$ were added to the wells and the cells were further incubated for $24 \mathrm{~h}$. After the incubation period, the media were discarded, and the cells were rinsed with 1X PBS. After removing PBS,
$20 \mu \mathrm{l}$ of $1 \mathrm{X}$ lysis reagent was dispensed into the wells and the cells were incubated with the lysis reagent for $10 \mathrm{~min}$. The luminescence in each well was recorded during $10 \mathrm{~s}$ upon introducing $100 \mu \mathrm{l}$ luciferase assay reagent using the dispenser of the luminometer. The data were presented as the average ( \pm standard deviation) of two or three separate experimental set-ups, each performed in triplicate.

pDNA (pIRES2-EGFP, $5.3 \mathrm{~kb}$ ) transfection efficiency of the polymers was determined by fluorescence microscopy and flow cytometry. For this aim, MDA-MB-231 or HEK 293T cells were seeded to 24-well plates at a concentration of $5 \times 10^{4}$ cells/well. After $48 \mathrm{~h}$, medium was removed and $475 \mu \mathrm{l}$ of fresh medium was added to the wells. Cells were transfected with $25 \mu \mathrm{l}$ of freshly prepared pDNA-polymer complexes (at N/P of 10 and 20 in case of PEI, and N/P of 50, 100 and 200 in case of P (AEAEMA)). pDNA-polymer complexes were prepared in the same way as siRNA-polymer complexes, using pDNA instead of siRNA. The pDNA concentration was kept the same for all wells $(50 \mathrm{nM})$. As a control, the same amount of only pDNA $(25 \mu \mathrm{l}, 50 \mathrm{nM})$ was added to the wells. $48 \mathrm{~h}$ post-transfection, GFP expression was investigated by fluorescence microscopy and flow cytometry. The assay was performed in duplicate.

Student's $t$-test (two-tailed) was used to analyse the data and $\mathrm{p}<$ 0.05 was considered statistically significant.

\section{Results and discussion}

\subsection{Synthesis and characterization of $P(A E A E M A)$}

The procedure reported by Kurtulus et al. was followed to obtain BocAEAEMA monomer and P(AEAEMA) polymer [34]. The protected polymer $\mathrm{P}$ (BocAEAEMA) was characterized using ${ }^{1} \mathrm{H}$ NMR spectroscopy and GPC (Supporting Information Fig. S1). GPC chromatogram showed a monomodal distribution of molecular weight with a slight low molecular weight tail. The $\mathrm{M}_{\mathrm{n}}$ and $Ð$ values of $\mathrm{P}($ BocAEAEMA) were determined to be $15.4 \mathrm{kDa}$ and 1.40 , respectively. The relatively large $Ð$ value might be attributed to the bulky structure of primary and secondary amine protected monomer. As reported before, for BocAEAEMA polymers, dispersity has been increased with the increase in molecular weight [34]. Particularly P(BocAEAEMA) homopolymers having an $\mathrm{M}_{n}$ above $10 \mathrm{kDa}$, have been found to have higher $Đ$ values which imply the restricted growing of the polymer chains above a certain polymerization degree. The Boc-protected polymer was then deprotected to yield $P$ (AEAEMA) using TFA. Removal of Boc groups from the polymer was verified by ${ }^{1} \mathrm{H}$ NMR spectroscopy (Supporting Information, Fig. S1). The disappearance of Boc group signals (around $1.43 \mathrm{ppm}$ ) on NMR spectrum proved that $\mathrm{P}$ (BocAEAEMA) was fully deprotected, revealing functional amine groups on the polymer. The molecular weight of the polymer after deprotection (P(AEAEMA)) was calculated theoretically assuming all Boc groups were removed. The mass of Boc groups were subtracted from the $\mathrm{M}_{\mathrm{n}}$ of $\mathrm{P}$ (BocAEAEMA) and the molecular weight of the deprotected polymer, P(AEAEMA), was found to be approximately 8 $\mathrm{kDa}(7870 \mathrm{~g} / \mathrm{mol})$.

\subsection{Effect of polymers on cell viability}

The cytotoxicity of P(AEAEMA)- $8 \mathrm{kDa}$ and PEI- $8 \mathrm{kDa}$ was investigated using Skov-3-luc human ovary cancer cell line (the model cell line used in this study for siRNA transfection assay), and NIH/3T3 mouse fibroblast cell line (a very commonly used cell line to evaluate cytotoxicity of polymers and nanoparticles) via a well-known cell viability assay, MTT. Five different concentrations of polymers $(2.5,5,10,20$ and $40 \mu \mathrm{M}$ ) were tested for $24 \mathrm{~h}$ or $72 \mathrm{~h}$ of incubation. The percent viability of the cells was determined with respect to the control wells containing untreated cells.

For both polymers, dose-dependent increase in cytotoxicity was observed (Fig. 1). Both cell lines exhibited the same toxicity profile. The viability of the P(AEAEMA) treated cells at the concentration of $20 \mu \mathrm{M}$ and below was found to be higher than $50 \%$ for $24 \mathrm{~h}$. Compared to this, 

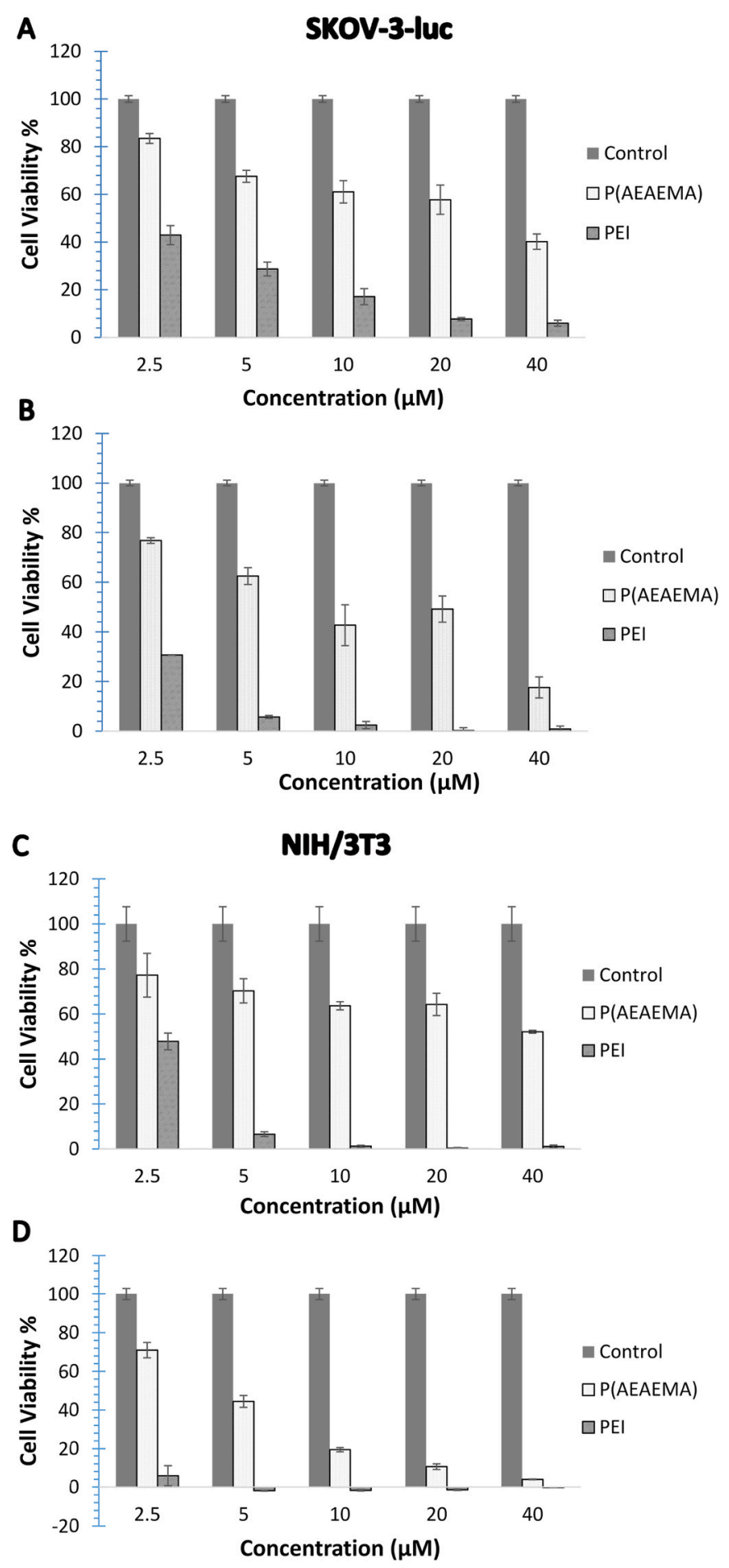

Fig. 1. The percent cell viability of Skov-3-luc (A,B) and NIH/3T3 (C,D) cell lines after incubation with polymers, PEI- $8 \mathrm{kDa}$ and P(AEAEMA)- $8 \mathrm{kDa}$, for $24 \mathrm{~h}$ $(\mathrm{A}, \mathrm{C})$ and $72 \mathrm{~h}(\mathrm{~B}, \mathrm{D})$.

PEI showed higher toxicity (cell viability $<50 \%$ ) at all tested concentrations. The difference between PEI and P(AEAEMA) was statistically significant at all concentrations for $24 \mathrm{~h}$ and $72 \mathrm{~h}$. At longer incubation period $(72 \mathrm{~h})$, the effect of polymer concentration was more profound (Fig. 1B and D). P(AEAEMA) did not reduce the cell viability below 70\% at a concentration of $2.5 \mu \mathrm{M}$. In contrast, the viability of cells treated with PEI was found to be drastically lower for all concentrations tested.

Protonation behaviour of polycations, particularly PEI, has been investigated both theoretically and experimentally by various research groups to understand the relationship between protonation and gene delivery efficiency of the carriers [16,22,24,40-42]. Although different and conflicting results have been shown in the literature regarding the protonation degree of linear PEI, approximately $50 \%$ of amine groups of linear PEI (having pKa of 6.6) have generally been accepted to be protonated at neutral physiological $\mathrm{pH}[22,40]$. Thus, PEI could complex the genetic material at neutral $\mathrm{pH}$ and still could be protonated at acidic $\mathrm{pH}$ and facilitate endosomal escape via protonation of free, uncomplexed amine groups. Similarly, the protonation capacity and pKa values of a DET containing polyaspartamide derivative polymer (PAsp(DET)) (which has the same pendant DET motif with P(AEAEMA)) have been studied by Kataoka and his group [22]. It was shown that $51 \%$ of DET's amine groups are protonated at neutral $\mathrm{pH}$ (pKa values of primary and secondary amines are 8.9 and 6.2, respectively) [22]. Therefore, the protonation degree of PEI and P(AEAEMA) can be assumed to be the same at physiological $\mathrm{pH}$. On the other hand, the same amount of PEI-8K (186 repeating units, $186 \mathrm{~mol}$ secondary amine) and P(AEAEMA)-8K (41 repeating units, a total of $82 \mathrm{~mol}$ of secondary and primary amines) have different amounts of amine density per mole of polymer. More specifically, PEI bears 2.2-fold more cationic charge compared to P(AEAEMA) which could be the reason for higher toxicity. Noticeably, P(AEAEMA) at $40 \mu \mathrm{M}$ showed approximately the same toxicity with PEI at $2.5 \mu \mathrm{M}$ (Fig. 1).

In summary, while low molecular weight liner PEI is known to be less toxic than its branched and high molecular weight counterpart [25,43], it showed significantly higher toxicity compared to P(AEAEMA) at all concentrations tested. Thus, P(AEAEMA) stands out as a safer cationic polymer which possesses promise for nucleic acid delivery.

\subsection{Polyplex formation with siRNA}

The ability of the P(AEAEMA) to form complexes with siRNA was investigated via gel electrophoresis. In order to determine the amount of polymer required to fully complex with siRNA, varying amounts of polymers were complexed with siRNA at a fixed concentration. Complexes prepared at varying nitrogen/phosphate (polymer/siRNA) ratios were analysed by gel electrophoresis. The results showed that $\mathrm{P}$ (AEAEMA) could efficiently complex with siRNA at an N/P ratio of 2 (Fig. 2A). As shown in the electropherogram, the siRNA band completely disappeared at N/P of 2 which indicated that the amount of polymer was enough to neutralize all siRNA molecules and all siRNA molecules participated in the complex formation with cationic polymer.

The complex forming ability of PEI-8 kDa was also investigated (Fig. 2B). PEI was also able to form complexes with siRNA at an N/P ratio of 2, however smear was observed until the $\mathrm{N} / \mathrm{P}$ ratio of 5 , indicating that all siRNA molecules were fully complexed with positively charged polymer, PEI-8 $\mathrm{kDa}$ only at an N/P of 5 .

Complex formation was studied by varying the N/P ratio. That is; a fixed amount of siRNA (0.02 nmoles) was interacted with varying amounts of PEI or P(AEAEMA) to eventually obtain complexes at the same N/P ratio. This result implies that, even though PEI and $P$ (AEAEMA) have the same amount of charged amine groups, $P$ (AEAEMA) could bind siRNA more effectively. This may be attributed to the presence of hydrophobic methacrylate backbone of P(AEAEMA) which might facilitate formation and stabilization of siRNA-polymer complex particles. Additionally, unlike PEI, P(AEAEMA) potentially offers more sterically available amine groups (as pendant groups), facilitating interactions with siRNA molecules.

Size and surface charge of the P(AEAEMA)-siRNA complexes at varying N/P ratios were also investigated (Table 1, Table S1 and Fig. S2) via dynamic light scattering measurements. Similar to other reports in the literature, the average diameter of the complexes did not show a trend that depends on N/P ratio [33,44]. Unimodal size distribution was observed for all P(AEAEMA)-siRNA complexes except the polyplex prepared at an N/P of 100 and 200. Since the polymer amount is highly increased at N/P of 100 and 200, bimodal distribution indicating the 
A

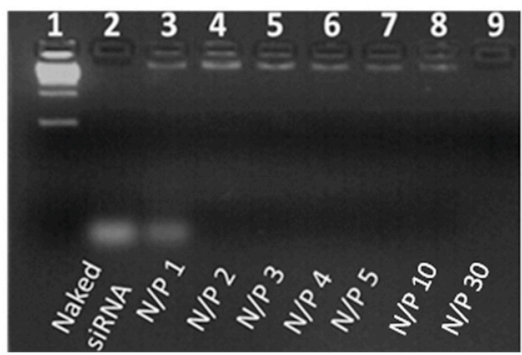

B

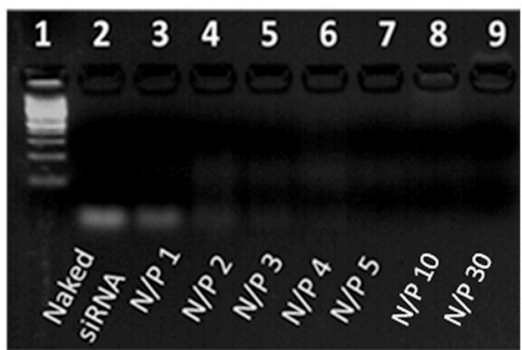

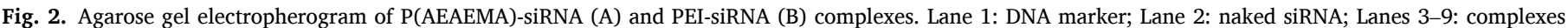
prepared at an $\mathrm{N} / \mathrm{P}$ ratio of $1,2,3,4,5,10$ and 30, respectively.

Table 1

The average intensity diameter of polyplexes determined by DLS.

\begin{tabular}{lll}
\hline N/P & P(AEAEMA)-siRNA complexes $(\mathrm{nm})$ & PEI-siRNA complexes $(\mathrm{nm})$ \\
\hline 2 & $199.6 \pm 3.2$ & $375.3 \pm 4.9$ \\
5 & $171.5 \pm 3.2$ & $787.4 \pm 24.4$ \\
10 & $155.0 \pm 13.4$ & $528.6 \pm 20.9$ \\
30 & $166.9 \pm 12.7$ & $323.0 \pm 44.0$ \\
50 & $213.6 \pm 26.8$ & $413.6 \pm 20.2$ \\
100 & $9.4 \pm 1.1$ & $5.7 \pm 0.5$ \\
& $588.5 \pm 142.9$ & $419.2 \pm 37.7$ \\
200 & $9.9 \pm 0.8$ & N/A \\
& $342.9 \pm 39.7$ & \\
\hline
\end{tabular}

existence of free polymer chains along with polyplexes was observed.

In contrast to P(AEAEMA)-siRNA complexes, the average hydrodynamic diameter of PEI-siRNA complexes was found to be significantly higher at almost all N/P ratios tested (except N/P of 100) (Table 1 and Fig. S3). This may suggest that the hydrophobic -C-C- backbone and brush architecture of P(AEAEMA) lead to the formation of more compact and smaller nanoparticles in the presence of siRNA molecules. This is also supported by PDI values of P(AEAEMA)-siRNA complexes which were relatively small in general (Table S2).

All polyplexes displayed positive zeta potential which was anticipated to enhance the cellular uptake of the complexes (Table S1). However, the positive zeta potential would also be expected to lead to non-specific interactions with serum components and aggregation of the complexes in serum containing media. While it is not the focus of this paper, this problem can be overcome by incorporating a neutral and hydrophilic polymer block such as PEG [45]. Similar to size results, the zeta potential values were between a certain range $(3.76-9.31 \mathrm{mV}$ ) and did not differ with the increase in N/P ratios.

\subsection{Stability of the polymer-siRNA complexes against serum components}

One of the important features that an ideal carrier for gene/nucleic acid delivery should have is the ability to protect siRNA against nucleases [46]. siRNA protecting ability of P(AEAEMA) against serum nucleases was investigated by agarose gel electrophoresis. For this purpose, the degradation rate of naked siRNA in FBS $(50 \% \mathrm{v} / \mathrm{v}$ in phosphate buffer) at $37{ }^{\circ} \mathrm{C}$ was first investigated. The aliquots of naked siRNA in FBS solution taken at determined times and inhibited with EDTA were run on the agarose gel.

The electropherogram showing the degradation of naked siRNA in serum with time is presented in Fig. 3. As it can be seen, degradation was not observed when siRNA was incubated in inactivated (EDTA treated) serum (Fig. 3 Lanes 6-9). In contrast to this, active serum degraded the naked siRNA at increasing extents with increasing incubation time (Fig. S4). According to ImageJ analysis results, $54 \%$ of the siRNA was degraded in the first $30 \mathrm{~min}$. In $4 \mathrm{~h}$, almost complete degradation of siRNA was observed ( $80 \%$ degradation).

The siRNA protection ability of P(AEAEMA) was investigated at two

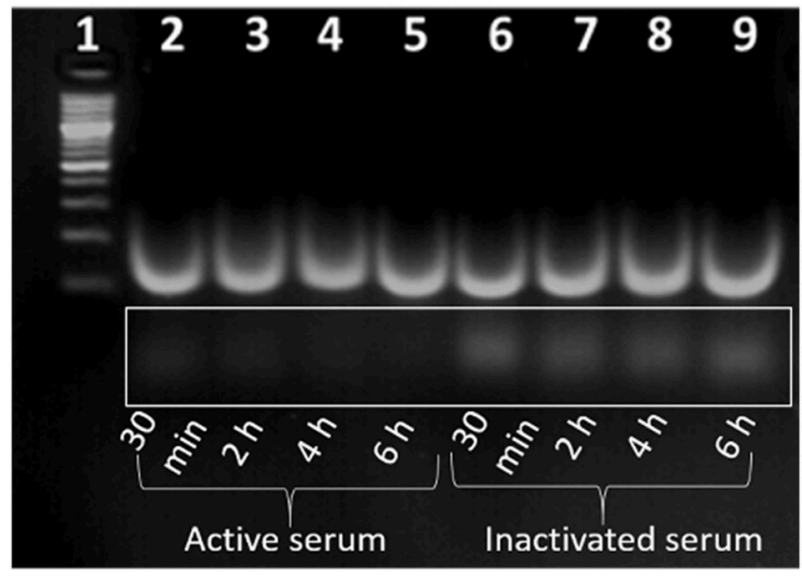

Fig. 3. Agarose gel electropherogram of naked siRNA in FBS. Lane 1: DNA marker; Lanes 2-5: siRNA incubated in active FBS at $37{ }^{\circ} \mathrm{C}$ during $30 \mathrm{~min}, 2 \mathrm{~h}$, $4 \mathrm{~h}$ and $6 \mathrm{~h}$, respectively; Lanes 6-9: siRNA incubated in inactivated FBS at $37{ }^{\circ} \mathrm{C}$ during $30 \mathrm{~min}, 2 \mathrm{~h}, 4 \mathrm{~h}$ and $6 \mathrm{~h}$, respectively.

different N/P ratios (2 and 10) via gel electrophoresis. At the end of the incubation periods, complexes were disassembled by adding SDS and the mixture was run on agarose gel. As it can be seen in the electropherogram, siRNA bands were clearly visible until $6 \mathrm{~h}$ which means polymers could protect the siRNA against nucleases at least for $6 \mathrm{~h}$ (Fig. 4). At longer incubation period ( $24 \mathrm{~h}$ ) the intensity of the band dramatically decreased which is indicating that almost all siRNA molecules were degraded by serum nucleases.

In brief, while naked siRNA was degraded by serum nucleases quite

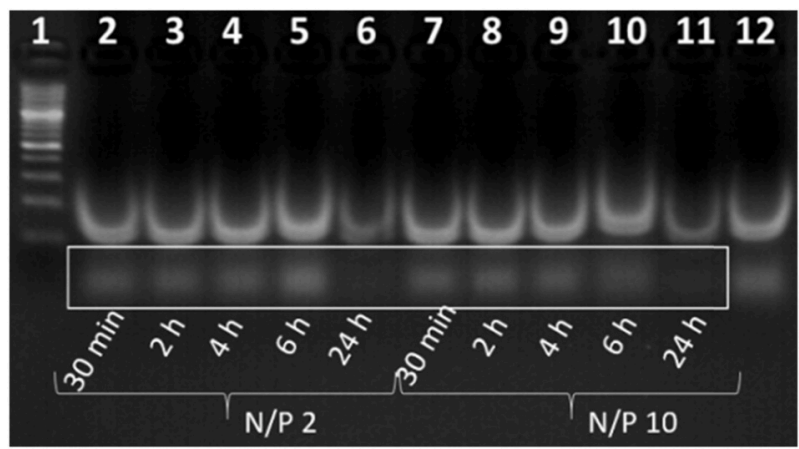

Fig. 4. Agarose gel electropherogram of P(AEAEMA)-siRNA in FBS. Lane 1: DNA marker; Lanes 2-6: complexes prepared at N/P of 2 and incubated in FBS at $37{ }^{\circ} \mathrm{C}$ during $30 \mathrm{~min}, 2 \mathrm{~h}, 4 \mathrm{~h}, 6 \mathrm{~h}$ and $24 \mathrm{~h}$, respectively; Lanes $7-11$ : complexes prepared at N/P of 10 and incubated in FBS at $37{ }^{\circ} \mathrm{C}$ during $30 \mathrm{~min}$, $2 \mathrm{~h}, 4 \mathrm{~h}, 6 \mathrm{~h}$ and $24 \mathrm{~h}$, respectively; Lane 12: control (complex prepared at N/P of 10 and loaded in inactivated FBS). 
rapidly, when it is complexed with $\mathrm{P}(\mathrm{AEAEMA})$, increase in resistance against nuclease degradation was observed. P(AEAMA) could shield the siRNA molecules even at lowest complexation N/P ratio by blocking the enzyme substrate interaction sterically, leading to increased stability of the siRNA in serum containing media which is necessary for successful gene delivery.

\subsection{Transfection efficiency of polymers}

The siRNA transfection efficiency of P(AEAEMA) was first determined using stably firefly luciferase expressing human ovary cancer cell line, Skov-3-luc, as a model cell line via luciferase assay. An antiluciferase siRNA sequence was used to selectively inhibit the expression of the luciferase gene. A non-targeting siRNA was used as a negative control. The transfection efficiency of two different commercial siRNA transfection reagents, lipofectamine RNAimax and DharmaFECT 3, and linear PEI $\left(\mathrm{M}_{\mathrm{n}}=8 \mathrm{~K}\right)$ was also determined and compared to P(AEAEMA). The reduction in luciferase expression level was determined by measuring the luminescence using Promega luciferase assay kit. The cytotoxicity of the complexes was also determined via MTT assay in parallel to luciferase assay.

The luciferase assay results of Skov-3-luc cell line were presented in Fig. 5. The luciferase expression level of the cells not treated was accepted as one hundred percent. The relative expression level of cells after treatment with transfection agents or polyplexes was determined in comparison with non-treated cells. As it can be seen in Fig. 5, when only siRNA was applied to the cells, luciferase expression of cells did not decrease. This was attributed to the instability of siRNA in serum containing media, as supported by serum stability assay results. However, when siRNA (25 nM) was complexed with the commercial transfection reagents, significant reduction in luciferase expression (reduced to $27 \%$ and $57 \%$ of the control, for Dharmafect ${ }^{\circledR}$ and RNAiMax ${ }^{\circledR}$, respectively) was observed which may be due to the enhanced stability, cellular uptake and/or cytosolic release, leading to the RNAi mechanism. Also, a siRNA having an irrelevant sequence (negative control) was used with the commercial reagents to show the specificity of the anti-luc siRNA sequence used in this study toward the firefly luciferase gene. When the cells were treated with the complexes formed by negative control siRNA and commercial reagents, no effect on the luciferase expression was observed, indicating that the decreased luciferase expression of cells treated with transfection agent-anti-luc siRNA sequence complexes was due to the specific gene silencing.

Polyplexes of P(AEAEMA) with siRNA (100 nM) at varying N/P ratios were tested on Skov-3-luc cell line. Polymer dose dependent decrease in luciferase expression was observed. In parallel with this, the cytotoxicity was also slightly increased with increasing polymer dose. At an N/P ratio of 2 (which was the lowest ratio at which complexes formed according to gel electrophoresis results), gene silencing effect could not be observed. At an N/P ratio of 50, the luciferase expression decreased to $77 \%$ while the polyplexes still did not show any toxic effect on the cells (cell viability $=93 \%$ ). When N/P ratio was increased to 200 , the gene silencing effect of the polyplexes was more clearly observed. At this N/P ratio, the luciferase expression decreased to $41 \%$. On the other hand, the cell viability also slightly reduced to $76 \%$. According to Student's $t$-test analysis results, the difference between viability and luciferase expression was found to be statistically significant $(\alpha=0.05)$ at all N/P ratios except $\mathrm{N} / \mathrm{P}$ of 2 . Hence, statistical analysis indicated that the decrease in the luciferase expression with increasing polymer concentration was not due to the increased toxicity.

The decrease in luciferase expression was directly proportional to the increase in polymer concentration. The increase in the amount of free polymer in the complex formulation clearly caused higher transfection efficiency at high N/P ratio (200). The presence of free polymer in complex formulation having N/P ratio of 200 was evidenced by DLS measurements as presented in Table 1 . Considering that the zeta potential, hydrodynamic volume and siRNA protection ability of the complexes prepared at varying N/P ratios did not differ significantly, the higher transfection ability of complexes prepared at an N/P ratio of 200 cannot be attributed to the enhanced siRNA protection or cellular uptake of these complexes. It might be possible that the increased polymer amount in this complex formulation leads to enhanced cytosolic release of siRNA molecules. Diaminoethane motif of P(AEAEMA) has been known to cause strong membrane destabilization effect at acidic endosomal pH [47].

The transfection efficiency of linear PEI $\left(\mathrm{M}_{\mathrm{n}}: 8 \mathrm{kDa}\right)$ was also investigated (Fig. 6). Similar to P(AEAEMA), PEI was not effective at the low N/P ratios. However, at N/P of 30 and 50, PEI could reduce the luciferase expression level to $57 \%$ and $54 \%$, respectively without showing significant toxicity (cell viability $95 \%$ and $90 \%$ ). When N/P ratio was increased to 100 , the toxicity of PEI-siRNA complexes significantly increased (cell viability $=63 \%$ ). On the other hand, luciferase expression level was less than $20 \%$ at this N/P ratio.

Since the transfection efficiency of the gene delivery vectors highly depends on the employed cell line, the gene silencing ability of $P$ (AEAEMA) in comparison with PEI has been further investigated using another cell line (MDA-MB-231-luc human breast cancer cell line stably

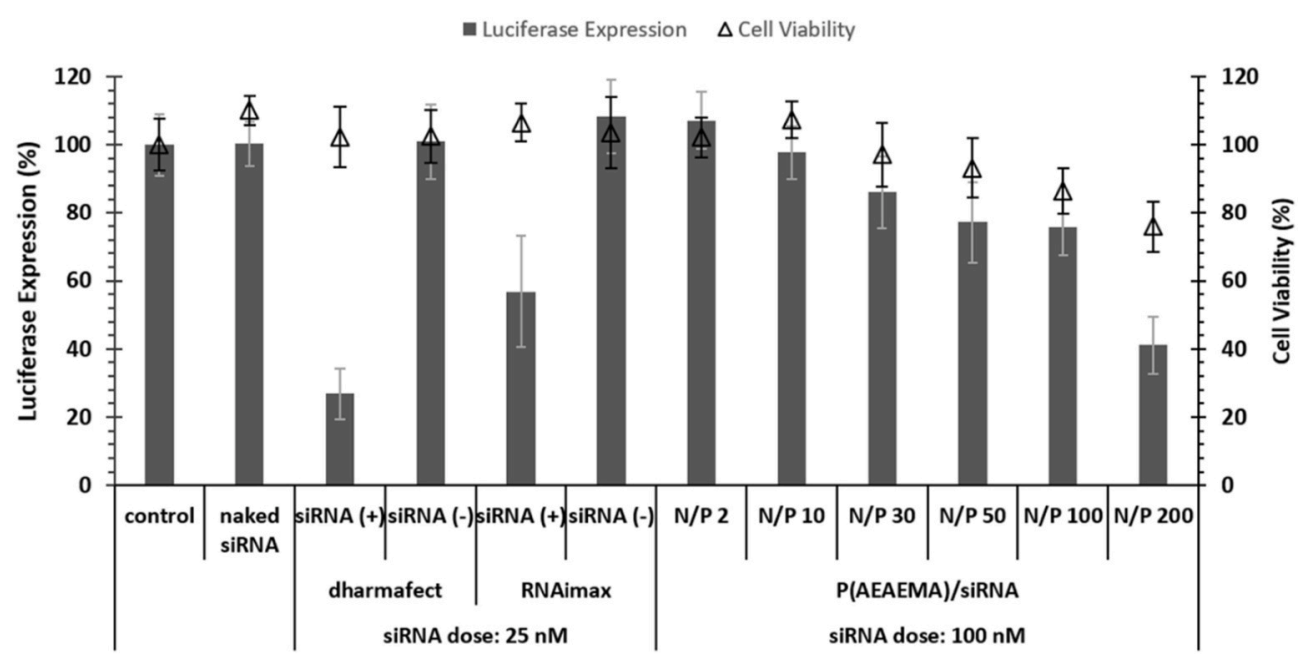

Fig. 5. The percent luciferase expression and cell viability of Skov-3-luc cell line after the treatment with naked siRNA, Dharmafect-siRNA complexes, RNAimaxsiRNA complexes or P(AEAEMA)-siRNA complexes at N/P of 2, 10,30,50, 100 and 200. siRNA(+) and siRNA(-) indicates the positive and negative control siRNA, respectively. 


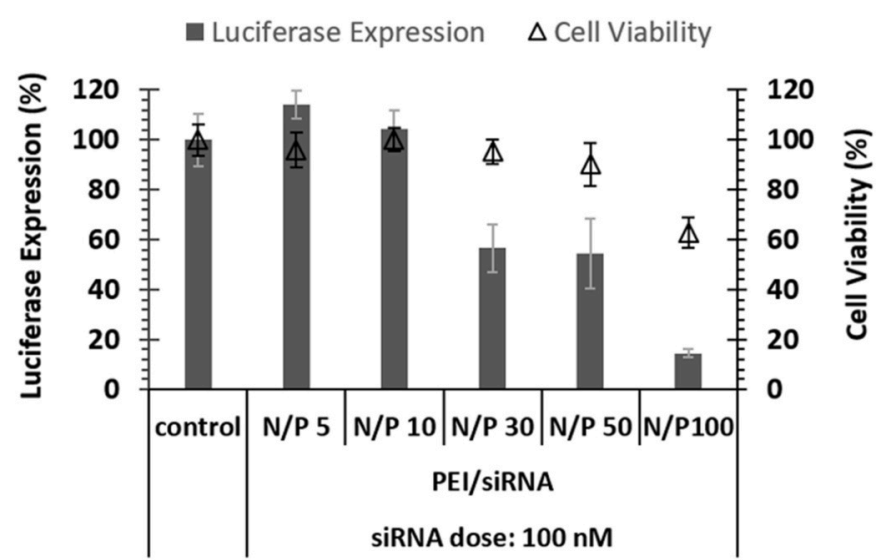

Fig. 6. The percent luciferase expression and viability of Skov-3-luc cell line after treatment with PEI-siRNA complexes at N/P of 5, 10,30, 50 and 100.

expressing luciferase) (Fig. S5). The same experimental method was employed. As it can be seen in Fig. S5, neither PEI nor P(AEAEMA) was able to reduce the luciferase expression of MDA-MB-231-luc without showing toxicity at tested concentrations and conditions. In contrast, the lipid-based transfection reagent Lipofectamine RNAiMax ${ }^{\circledR}$ was able to show potent transfection efficiency. The data suggested that the transfection ability of both PEI and P(AEAEMA) was cell-type dependent.
To further support this finding and also prove the nucleic acid delivery potential of newly presented P(AEAEMA), MDA-MB-231 cell line and a human embryonic kidney cell line (HEK 293T) were transfected with plasmid DNA (pDNA) complexes of both P(AEAEMA)-8 kDa and PEI-8 kDa (Fig. 7, Fig. 8, Fig. S6 and Fig. S7). pDNA transfection efficiency was determined by evaluating the GFP expression via fluorescence microscopy and flow cytometry. Naked pDNA was used as a control. pDNA ( $50 \mathrm{nM}$ ) was complexed with PEI at an N/P ratio of 20 and 10. At N/P of 20, PEI-pDNA polyplexes were just below their toxic threshold (cell viability $\geq 70 \%$ ), and at N/P of 10 , the polyplexes were in safe range (Fig. S7). In case of $\mathrm{P}(\mathrm{AEAEMA})$, the N/P ratio was kept higher, similar to siRNA transfection assay, as P(AEAEMA) was not toxic at all at the tested ratios (Fig. 8B and Fig. S7). P(AEAEMA)-pDNA complexes showed negligible toxicity even at N/P of 400, 800 and, 1600 (cell viability $\geq 85 \%$ ) (Fig. S7). Additionally, it was previously shown that P(AEAEMA)-5K or P(AEAEMA)-10K was able to complex completely with a DNA fragment of $700 \mathrm{bp}$ at an N/P ratio of 10 and above [34].

The results of pDNA transfection of MDA-MB-231 cell line, determined by flow cytometry, are shown in Fig. S6. Same with siRNA transfection, both polymers showed almost no pDNA transfection efficiency on MDA-MB-231 cells. Compared to MDA-MB-231, GFP-coding pDNA transfection of HEK 293T cells was significant for both $P$ (AEAEMA) and PEI (Figs. 7 and 8). Both fluorescence microscopy and flow cytometry data clearly indicated the potential of P(AEAEMA) as a safer alternative for nucleic acid delivery. They also revealed that the
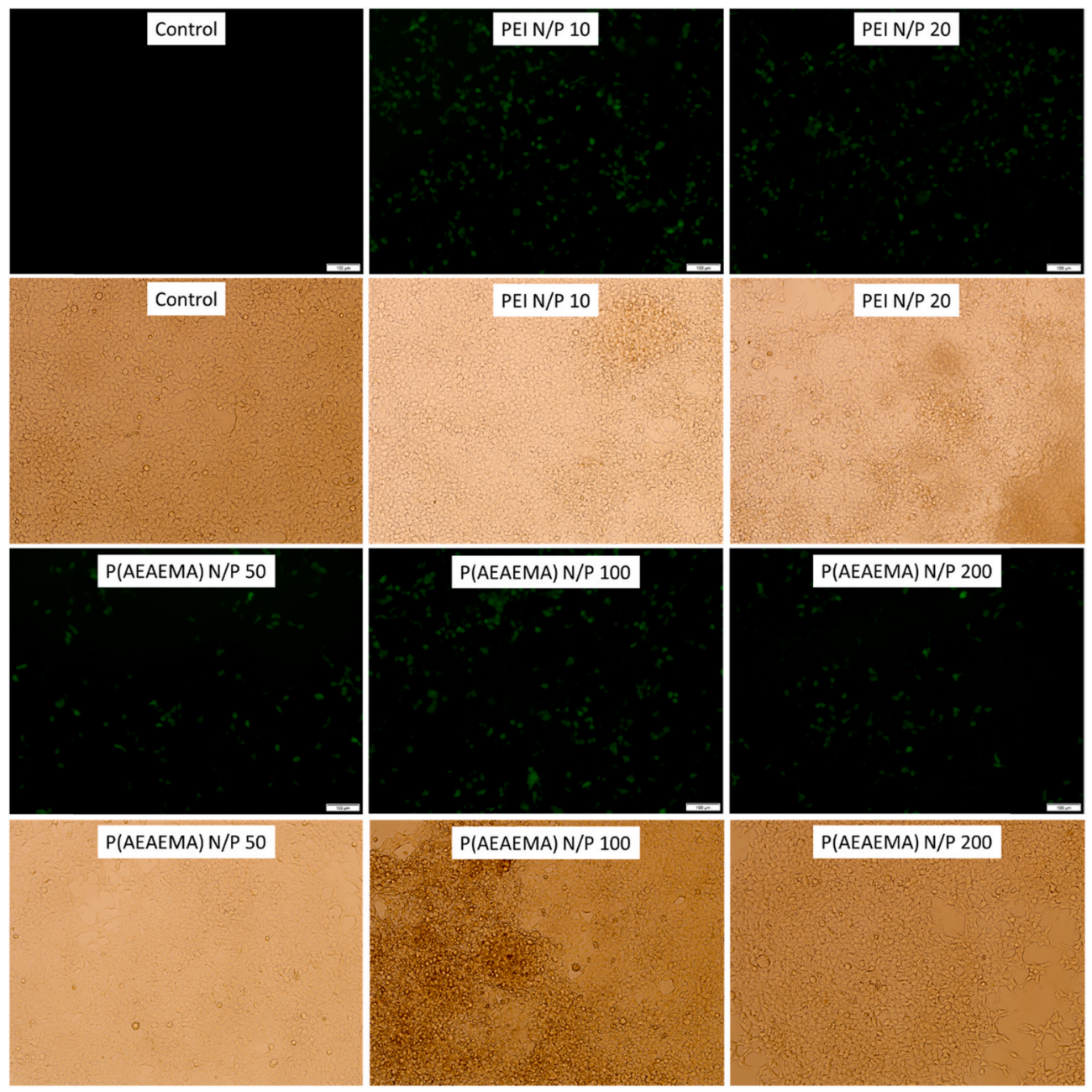

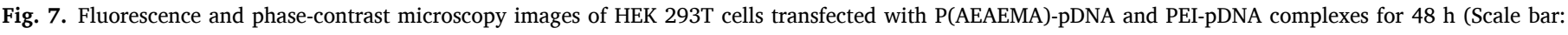
$100 \mu \mathrm{m})$. 
A
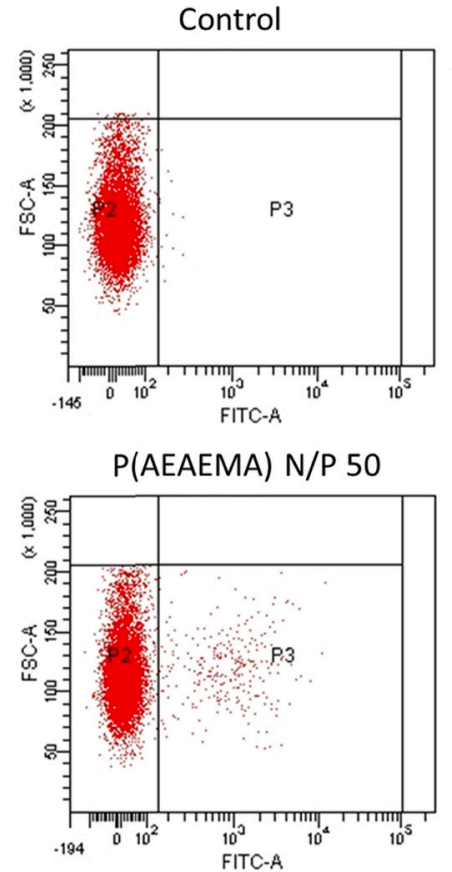

PEI N/P 10
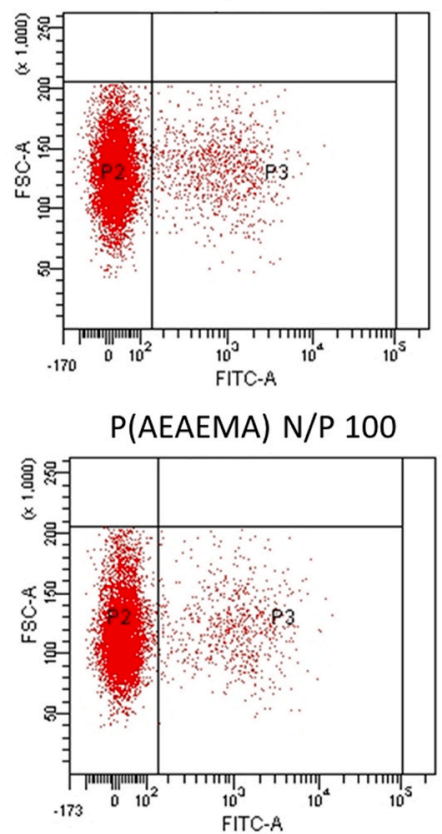

PEI N/P 20

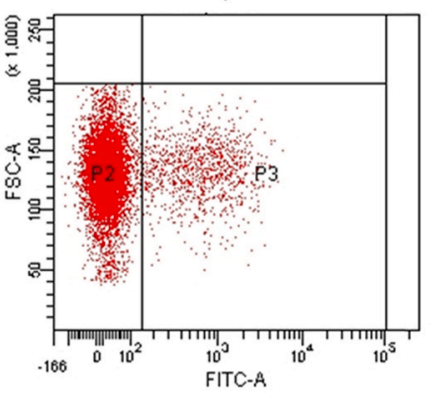

\section{P(AEAEMA) N/P 200}

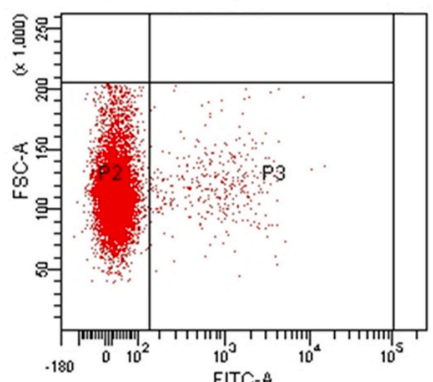

B

- GFP Positive Cells $\Delta$ Cell Viability

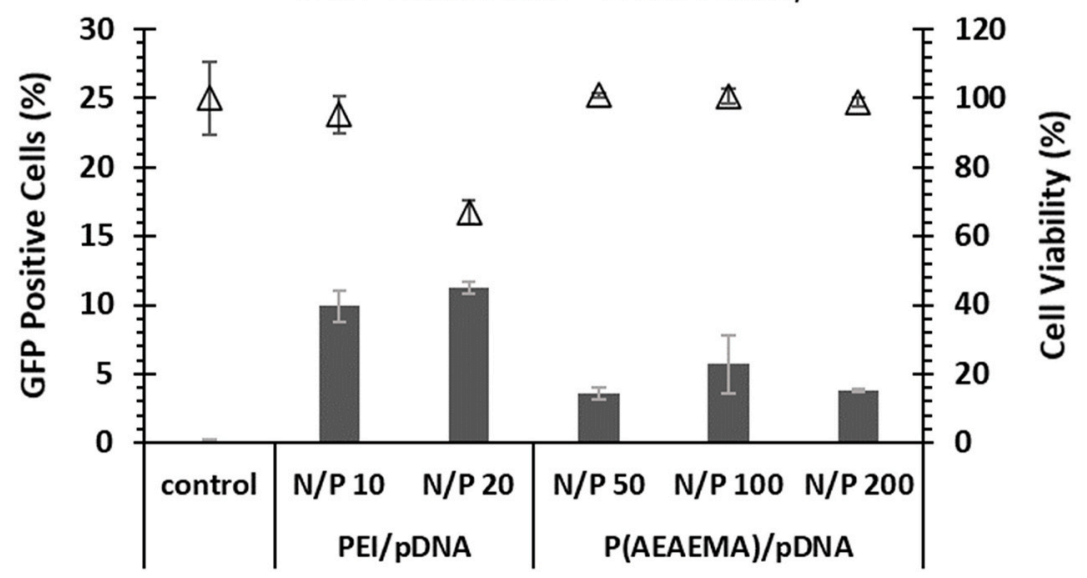

Fig. 8. Representative flow cytometer plots (A) and pDNA transfection results (B) of HEK 293T cells treated with P(AEAEMA)-pDNA and PEI-pDNA complexes for 48 h. GFP expression was determined by flow cytometry (A) and the data were quantified accordingly (B).

transfection efficiency of both PEI and P(AEAEMA) was highly dependent on the cell line used.

The pDNA transfection efficiency of P(AEAEMA) or PEI did not significantly differ with respect to $\mathrm{N} / \mathrm{P}$ ratios suggesting that the maximum efficiency was reached at the tested conditions (Figs. 7 and 8). While we did not attempt to optimize the conditions in the current study, further research towards the optimization of some important parameters such as the number of polyplexes per cell and pDNA concentration needs to be performed in future. As it can be seen in the flow cytometer plots and fluorescence microscope images (Figs. 7 and 8), both polymers were able to transfect HEK 293T cells with pDNA as evidenced by GFP expression. The percentage of GFP expressing cells was quantified using flow cytometry (Fig. 8B). PEI was generally found to be more efficient compared to P(AEAEMA) at tested conditions. However, statistical analysis performed via students t-test indicated that there was no statistically significant difference between PEI (at N/P of 10 or 20) and P (AEAEMA) (at N/P of 100). In contrast to this, the difference was statistically significant at other N/P ratios indicating slightly higher efficiency of PEI. On the other hand, it should be noted that PEI complexes reduced the cell viability to $77 \%$ at N/P of 20 while P(AEAEMA) complexes did not really affect the cell viability even at the highest N/P ratio of 1600 (Fig. S7). Overall, PEI and P(AEAEMA) showed cell-line dependent efficiency for transfection of both siRNA and pDNA. While P(AEAEMA) was found to be slightly less effective than PEI in terms of transfection, considering significantly less toxic nature of P(AEAEMA) and other presented advantages of P(AEAEMA), it might be a preferable cationic block alternative to PEI.

\section{Conclusions}

In this study, a diaminoethane motif bearing methacrylate-based polymer, namely poly(2-((2-aminoethyl)amino)ethyl methacrylate) (P (AEAEMA)), synthesized via RAFT polymerization was evaluated as a potential nucleic acid delivery agent in comparison to a well-known 
gene delivery agent, linear PEI. P(AEAEMA) $\left(\mathrm{M}_{\mathrm{n}} 8 \mathrm{kDa}\right)$ showed almost no cytotoxicity at the concentrations at which linear PEI $\left(\mathrm{M}_{\mathrm{n}} 8 \mathrm{kDa}\right)$ was highly toxic. P(AEAEMA) could form complexes with siRNA at an N/P ratio of 2 which was 2.5 -fold lower than LPEI. The hydrodynamic diameter of P(AEAEMA)-siRNA complexes was found to be significantly lower than PEI-siRNA complexes almost at all N/P ratios tested and all polyplexes of P(AEAEMA) displayed positive zeta potential. P(AEAEMA) could protect the siRNA against nucleases and improved the stability of free siRNA even at an N/P ratio of 2 . The siRNA and pDNA transfection efficiency of P(AEAEMA)-8K was found to be comparable to or slightly less than PEI-8K at the tested conditions. Importantly, the transfection efficiency of both PEI and P(AEAEMA) was found to be highly dependent on the cell line used.

P(AEAEMA), with its favourable features such as ease of synthesis via RAFT polymerization offering structural tailoring ability for desired applications, partially-degradable nature, significantly low toxicity, high complex forming ability, and comparable transfection efficiency show promise as an alternative to linear PEI. P(AEAEMA) can be incorporated with neutral and hydrophilic polymers such as PEG to minimize interactions with serum components to formulate better nucleic acid carriers. Compared to linear PEI, linear P(AEAEMA) contains sterically more available primary and secondary amines along with methacrylate backbone which could facilitate the complexation with nucleic acids and potentially enhance stability of polyplex particles. In conclusion, considering all these properties, P(AEAEMA)-8K is potentially a viable alternative to linear PEI-8K for nucleic acid delivery.

\section{CRediT authorship contribution statement}

Aykut Zelcak: Methodology, Validation, Investigation, Writing original draft. Yagmur Ceren Unal: Investigation. Gulistan Mese: Resources, Writing - review \& editing. Volga Bulmus: Conceptualization, Methodology, Writing - review \& editing, Supervision, Funding acquisition.

\section{Declaration of competing interest}

The authors declare that they have no known competing financial interests or personal relationships that could have appeared to influence the work reported in this paper.

\section{Acknowledgements}

The authors acknowledge The Scientific and Technological Research Council of Turkey (TUBITAK) for funding through the grant\# 115R301. The authors also acknowledge Biotechnology and Bioengineering Application and Research Centre (Izmir Institute of Technology, Turkey) for cell culture facilities, and Prof. Özgür Şahin (Bilkent University), Prof. Sacide Altinkaya (Izmir Institute of Technology) and Assoc. Prof. Ozden Yalcin-Ozuysal (Izmir Institute of Technology) for providing MDA-MB-231-luc, Skov-3-luc and HEK 293T cell lines, respectively.

\section{Appendix A. Supplementary data}

Supplementary data to this article can be found online at https://doi. org/10.1016/j.jddst.2021.102551.

\section{References}

[1] J. Daley, Gene therapy arrives, Nature 576 (7785) (2019) S12-S13.

[2] C.E. Dunbar, K.A. High, J.K. Joung, D.B. Kohn, K. Ozawa, M. Sadelain, Gene therapy comes of age, Science 359 (6372) (2018).

[3] C. Li, R.J. Samulski, Engineering adeno-associated virus vectors for gene therapy, Nat. Rev. Genet. 21 (4) (2020) 255-272.

[4] B.E. Deverman, B.M. Ravina, K.S. Bankiewicz, S.M. Paul, D.W. Sah, Gene therapy for neurological disorders: progress and prospects, Nat. Rev. Drug Discov. 17 (9) (2018) 641-659.
[5] R.L. Setten, J.J. Rossi, S.-p. Han, The current state and future directions of RNAibased therapeutics, Nat. Rev. Drug Discov. 18 (6) (2019) 421-446.

[6] A. Wittrup, J. Lieberman, Knocking down disease: a progress report on siRNA therapeutics, Nat. Rev. Genet. 16 (9) (2015) 543.

[7] Y. Dong, D.J. Siegwart, D.G. Anderson, Strategies, design, and chemistry in siRNA delivery systems, Adv. Drug Deliv. Rev. 144 (2019) 133-147.

[8] D. Scherman, A. Rousseau, P. Bigey, V. Escriou, Genetic pharmacology: progresses in siRNA delivery and therapeutic applications, Gene Ther. 24 (3) (2017) 151-156.

[9] G. Ozcan, B. Ozpolat, R.L. Coleman, A.K. Sood, G. Lopez-Berestein, Preclinical and clinical development of siRNA-based therapeutics, Adv. Drug Deliv. Rev. 87 (2015) $108-119$.

[10] C. Lorenzer, M. Dirin, A.-M. Winkler, V. Baumann, J. Winkler, Going beyond the liver: progress and challenges of targeted delivery of siRNA therapeutics, J. Contr. Release 203 (2015) 1-15.

[11] S.F. Dowdy, Overcoming cellular barriers for RNA therapeutics, Nat. Biotechnol, 35 (3) (2017) 222.

[12] A. Akinc, M.A. Maier, M. Manoharan, K. Fitzgerald, M. Jayaraman, S. Barros, S. Ansell, X. Du, M.J. Hope, T.D. Madden, The Onpattro story and the clinical translation of nanomedicines containing nucleic acid-based drugs, Nat. Nanotechnol. 14 (12) (2019) 1084-1087.

[13] Y. Dong, T. Yu, L. Ding, E. Laurini, Y. Huang, M. Zhang, Y. Weng, S. Lin, P. Chen, D. Marson, A dual targeting dendrimer-mediated siRNA delivery system for effective gene silencing in cancer therapy, J. Am. Chem. Soc. 140 (47) (2018) 16264-16274.

[14] P. Zhang, K. An, X. Duan, H. Xu, F. Li, F. Xu, Recent advances in siRNA delivery for cancer therapy using smart nanocarriers, Drug Discov. Today 23 (4) (2018) 900-911.

[15] A. Kargaard, J.P. Sluijter, B. Klumperman, PolymericsiRNA gene delivery-transfection efficiency versus cytotoxicity, J. Contr. Release 316 (2019) 263-291. ISSN 0168-3659, https://doi.org/10.1016/j.jconrel.2019.10.046.

[16] H.J. Kim, A. Kim, K. Miyata, K. Kataoka, Recent progress in development of siRNA delivery vehicles for cancer therapy, Adv. Drug Deliv. Rev. 104 (2016) 61-77.

[17] S.J. Lee, M.J. Kim, I.C. Kwon, T.M. Roberts, Delivery strategies and potential targets for siRNA in major cancer types, Adv. Drug Deliv. Rev. 104 (2016) 2-15.

[18] B.R. Olden, Y. Cheng, L.Y. Jonathan, S.H. Pun, Cationic polymers for non-viral gene delivery to human T cells, J. Contr. Release 282 (2018) 140-147.

[19] D.W. Pack, A.S. Hoffman, S. Pun, P.S. Stayton, Design and development of polymers for gene delivery, Nat. Rev. Drug Discov. 4 (7) (2005) 581.

[20] G. Cavallaro, C. Sardo, E.F. Craparo, B. Porsio, G. Giammona, Polymeric nanoparticles for siRNA delivery: production and applications, Int. J. Pharm. 525 (2) (2017) 313-333.

[21] O. Boussif, F. Lezoualc'h, M.A. Zanta, M.D. Mergny, D. Scherman, B. Demeneix, J.P. Behr, A versatile vector for gene and oligonucleotide transfer into cells in culture and in vivo: polyethylenimine, Proc. Natl. Acad. Sci. Unit. States Am. 92 (16) (1995) 7297-7301.

[22] K. Miyata, N. Nishiyama, K. Kataoka, Rational design of smart supramolecular assemblies for gene delivery: chemical challenges in the creation of artificial viruses, Chem. Soc. Rev. 41 (7) (2012) 2562-2574.

[23] Q. Peng, Z. Zhong, R. Zhuo, Disulfide cross-linked polyethylenimines (PEI) prepared via thiolation of low molecular weight PEI as highly efficient gene vectors, Bioconjugate Chem. 19 (2) (2008) 499-506.

[24] U. Lungwitz, M. Breunig, T. Blunk, A. Göpferich, Polyethylenimine-based non-viral gene delivery systems, Eur. J. Pharm. Biopharm. 60 (2) (2005) 247-266.

[25] S. Werth, B. Urban-Klein, L. Dai, S. Höbel, M. Grzelinski, U. Bakowsky, F. Czubayko, A. Aigner, A low molecular weight fraction of polyethylenimine (PEI) displays increased transfection efficiency of DNA and siRNA in fresh or lyophilized complexes, J. Contr. Release 112 (2) (2006) 257-270.

[26] K. Kunath, A. von Harpe, D. Fischer, H. Petersen, U. Bickel, K. Voigt, T. Kissel, Lowmolecular-weight polyethylenimine as a non-viral vector for DNA delivery: comparison of physicochemical properties, transfection efficiency and in vivo distribution with high-molecular-weight polyethylenimine, J. Contr. Release 89 (1) (2003) 113-125.

[27] M. Breunig, U. Lungwitz, R. Liebl, C. Fontanari, J. Klar, A. Kurtz, T. Blunk, A. Goepferich, Gene delivery with low molecular weight linear polyethylenimines, J. Gene Med.: Cross-Discipl. J. Res. Sci. Gene Transf. Clin. Appl. 7 (10) (2005) 1287-1298.

[28] E. Wagner, Polymers for siRNA delivery: inspired by viruses to be targeted, dynamic, and precise, Accounts Chem. Res. 45 (7) (2011) 1005-1013.

[29] K. Miyata, M. Oba, M. Nakanishi, S. Fukushima, Y. Yamasaki, H. Koyama, N. Nishiyama, K. Kataoka, Polyplexes from poly (aspartamide) bearing 1, 2-diaminoethane side chains induce $\mathrm{pH}$-selective, endosomal membrane destabilization with amplified transfection and negligible cytotoxicity, J. Am. Chem. Soc. 130 (48) (2008) 16287-16294.

[30] G.-W. Jin, H. Koo, K. Nam, H. Kim, S. Lee, J.-S. Park, Y. Lee, PAMAM dendrimer with a 1, 2-diaminoethane surface facilitates endosomal escape for enhanced pDNA delivery, Polymer 52 (2) (2011) 339-346.

[31] K. Hayakawa, S. Uchida, T. Ogata, S. Tanaka, K. Kataoka, K. Itaka, Intrathecal injection of a therapeutic gene-containing polyplex to treat spinal cord injury, J. Contr. Release 197 (2015) 1-9.

[32] K. Itaka, S. Ohba, K. Miyata, H. Kawaguchi, K. Nakamura, T. Takato, U.-I. Chung, K. Kataoka, Bone regeneration by regulated in vivo gene transfer using biocompatible polyplex nanomicelles, Mol. Ther. 15 (9) (2007) 1655-1662.

[33] N. Kanayama, S. Fukushima, N. Nishiyama, K. Itaka, W.D. Jang, K. Miyata, Y. Yamasaki, U.i. Chung, K. Kataoka, A PEG-based biocompatible block catiomer with high buffering capacity for the construction of polyplex micelles showing 
efficient gene transfer toward primary cells, ChemMedChem, Chem. Enabl. Drug Discov. 1 (4) (2006) 439-444.

[34] I. Kurtulus, G. Yilmaz, M. Ucuncu, M. Emrullahoglu, C.R. Becer, V. Bulmus, A new proton sponge polymer synthesized by RAFT polymerization for intracellular delivery of biotherapeutics, Polym. Chem. 5 (5) (2014) 1593-1604.

[35] H.J. Kim, A. Ishii, K. Miyata, Y. Lee, S. Wu, M. Oba, N. Nishiyama, K. Kataoka, Introduction of stearoyl moieties into a biocompatible cationic polyaspartamide derivative, PAsp (DET), with endosomal escaping function for enhanced siRNAmediated gene knockdown, J. Contr. Release 145 (2) (2010) 141-148.

[36] C. Scholz, E. Wagner, Therapeutic plasmid DNA versus siRNA delivery: common and different tasks for synthetic carriers, J. Contr. Release 161 (2) (2012) 554-565.

[37] S. Lu, V.B. Morris, V. Labhasetwar, Codelivery of DNA and siRNA via arginine-rich PEI-based polyplexes, Mol. Pharm. 12 (2) (2015) 621-629.

[38] A. Kwok, A comparison of the properties of plasmid DNA and siRNA. DNA and RNA nanobiotechnologies in medicine: diagnosis and treatment of diseases. Heidelberg, Springer, Berlin, Germany, 2013, pp. 215-216.

[39] C. Boyer, V. Bulmus, T.P. Davis, Efficient usage of thiocarbonates for both the production and the biofunctionalization of polymers, Macromol. Rapid Commun. 30 (7) (2009) 493-497.

[40] J.D. Ziebarth, Y. Wang, Understanding the protonation behavior of linear polyethylenimine in solutions through Monte Carlo simulations, Biomacromolecules 11 (1) (2009) 29-38.

[41] P. Neuberg, A. Kichler, Recent developments in nucleic acid delivery with polyethylenimines, Adv. Genet. (2014) 263-288. Elsevier.
[42] L. Du, C. Wang, L. Meng, Q. Cheng, J. Zhou, X. Wang, D. Zhao, J. Zhang, L. Deng, Z. Liang, The study of relationships between pKa value and siRNA delivery efficiency based on tri-block copolymers, Biomaterials 176 (2018) 84-93.

[43] R. Deng, Y. Yue, F. Jin, Y. Chen, H.-F. Kung, M.C. Lin, C. Wu, Revisit the complexation of PEI and DNA - how to make low cytotoxic and highly efficient PEI gene transfection non-viral vectors with a controllable chain length and structure? J. Contr. Release 140 (1) (2009) 40-46.

[44] C. Wang, W. Yuan, F. Xiao, Y. Gan, X. Zhao, Z. Zhai, X. Zhao, C. Zhao, P. Cui, T. Jin, Biscarbamate cross-linked low-molecular-weight polyethylenimine for delivering anti-chordin siRNA into human mesenchymal stem cells for improving bone regeneration, Front. Pharmacol. 8 (2017) 572.

[45] C.-L. Chan, R.N. Majzoub, R.S. Shirazi, K.K. Ewert, Y.-J. Chen, K.S. Liang, C. R. Safinya, Endosomal escape and transfection efficiency of PEGylated cationic liposome-DNA complexes prepared with an acid-labile PEG-lipid, Biomaterials 33 (19) (2012) 4928-4935.

[46] D.J. Gary, N. Puri, Y.-Y. Won, Polymer-based siRNA delivery: perspectives on the fundamental and phenomenological distinctions from polymer-based DNA delivery, J. Contr. Release 121 (1-2) (2007) 64-73.

[47] H. Uchida, K. Miyata, M. Oba, T. Ishii, T. Suma, K. Itaka, N. Nishiyama, K. Kataoka, Odd-even effect of repeating aminoethylene units in the side chain of N-substituted polyaspartamides on gene transfection profiles, J. Am. Chem. Soc. 133 (39) (2011) 15524-15532. 